Revista de Investigación Educativa 28

enero-junio, 2019 | ISSN 1870-5308 | Xalapa, Veracruz

Instituto de Investigaciones en Educación | Universidad Veracruzana

\title{
¿Formación integral en la universidad? La voz de los estudiantes de una universidad privada de Mérida
}

\author{
Integral formation at university? \\ The voice of students from a private university in Mérida
}

\section{Rubi Shantal Torres Cardeña}

Recibido: 06 de julio de 2018

Aceptado: 10 de noviembre de 2018

DOI: https://doi.org/10.25009/cpue.v0i28.2601

Las instituciones de educación superior están conscientes de la necesidad de promover la Formación Integral (FI) en sus estudiantes y desarrollan acciones para lograrlo; sin embargo, poco se sabe acerca de la manera como los alumnos perciben este tipo de formación. Escuchar la voz de los jóvenes puede ser una condición que mejore las posibilidades y el éxito de la educación integral. Este artículo refleja avances de una investigación con diseño fenomenológico que pretende explicitar las experiencias y elementos que los universitarios vinculan a los significados que han construido de formación integral. Los participantes son cinco alumnos de una universidad privada de Mérida pertenecientes a carreras que representan las diversas áreas del conocimiento. Los resultados de este trabajo apuntan a que la Fi se construye desde: las dimensiones de la persona que impacta, los aspectos de la vida universitaria que involucra y las experiencias personales y académicas con que se relaciona.

Palabras clave: Educación integral; universidades; desarrollo humano; desarrollo del estudiante.

a Maestra en Educación. Coordinación de Modelo Educativo, Universidad Marista de Mérida, México.凶 rtorres@marista.edu.mx 
Higher education institutions are aware of the necessity of promoting student's integral formation and seek actions to achieve it. However, there is little awareness of how the students perceive this kind of development. To improve the possibilities of success in the attempts of achieving it, it could be important to listen to the students. This article presents research advances of a phenomenological study that seeks to explain the elements that the students link to the meaning of integral formation. The participants are five students from a private university in Mérida of different majors. The results suggest that the integral formation is linked to the dimensions of the subject that it impacts, the aspects of the college life that involves and the personal and academic experiences linked to it.

Keywords: Integral formation; colleges; human development; student development. \\ ¿Formación integral en la universidad? \\ La voz de los estudiantes de una universidad privada de Mérida
}

\author{
Integral formation at university? \\ The voice of students from a private university in Mérida
}

\title{
Contexto
}

a educación y Formación Integral (FI) son términos que generalmente tienden a
homologarse. Para esta investigación se toma el término Fi como aquel proceso que incluye a la persona en la totalidad de su historia y experiencias de vida (formación desde casa) las cuales se integran a la educación formal como un proceso que es continuo, permanente y participativo con la comunidad, que busca desarrollar de manera deliberada todas las dimensiones de la persona, desde un marco de respeto y dignificación de la misma.

En relación con este concepto, la universidad participante concibe desde sus principios ontológicos un ser humano que se construye a través del diálogo, el ser- 
vicio y los cuidados hacia el entorno, basado en el respeto a un ser humano capaz de ser crítico de su propia historia y construir en torno a ésta un contexto más justo y equitativo.

\section{Introducción}

En este trabajo se presenta un estudio fenomenológico que pretende comprender la forma como los universitarios explicitan los conceptos y significados que han construido sobre formación integral. Los desafíos que la sociedad contemporánea les plantea a los jóvenes profesionistas son complejos; se espera que los universitarios estén preparados para enfrentarlos. El actual, es un mundo enmarcado por la importancia del presente y la desesperanza del futuro; ante éste, la formación integral debe aportar elementos para restaurar la ilusión y compromiso por seguir construyendo (López, 2014). De frente a esta realidad, se espera que la universidad incluya en sus propósitos curriculares y extracurriculares la promoción de procesos en los que cada estudiante en individual y colectivo se descubra como un ser movido por el deseo de conocer la realidad del mundo; que se experimente como un ser impulsado por el deseo de tomar buenas decisiones y que a partir de estas experiencias se capacite para ser competente y auténtico en el deseo de conocer y de buscar el bien (Lonergan, 1999). Es difícil establecer una sola manera perfecta para la formación, pues no hay un tipo único de sociedad o persona; las habilidades, talentos, capacidades, conocimientos y gustos son diferentes para todos. En esta línea, las instituciones de educación superior empiezan a considerar modelos de formación pertinentes para esos entornos cambiantes, dando respuesta a las necesidades de los estudiantes y su papel en la sociedad (Orozco, 1999).

\section{¿Por qué sigue vigente la formación integral en la universidad?}

Por su naturaleza, el hombre requiere de un proceso de formación para su crecimiento intelectual, social, personal e incluso espiritual, y se considera que la educación es el recurso diseñado para lograr estos objetivos (Nova, 2017). De acuerdo con Martínez (2009), la educación puede ser considerada como integral si tiene en cuenta el desarrollo de los siguientes aspectos en la persona: 1) cognitivos, como la inteligencia y la creatividad; 2) psicológicos, considerando la parte afectivo-social; 3) moral, el 
cual incluye la ética y los valores; 4) vocacional y profesional. Morin (1999), había ya propuesto esta idea del hombre multidimensional, como un ser complejo que es "a la vez biológico, psíquico, social, afectivo y racional” (p. 16). Cuando las ciencias humanas se fragmentan, se pierde esta concepción del ser humano como unidad compleja, por esto se espera una educación capaz de concentrar sus funciones en una formación que tenga como centro al estudiante desde su ser individual, social e histórico, un ser humano desde sus múltiples dimensiones.

Misas (2004) considera como elementos importantes para lograr esta formación multidimensional, que las universidades incluyan en sus objetivos la generación de pensamiento científico, incrementar las experiencias de investigación que permitan desarrollar el conocimiento; gestionar saberes dentro del clima social y cultural, movilizar valores por medio de la formación ética, estética y científica que a su vez generen capacidades creativas en el individuo; tratar con la misma importancia aspectos sociales, intelectuales y espirituales que aportan al crecimiento humano; superar la especial atención que se tiene hacia los conceptos, teorías y habilidades centradas en la disciplina que desvalorizan el rol de materias que abonan a la formación humana, y actividades que se enfocan en aprender a ser, a convivir y a transformar (Nova, 2017). Las funciones de la educación son el escenario perfecto para formar mejores ciudadanos y garantizar en términos generales la evolución y sostenibilidad del mundo (Pérez, 2011).

\section{¿Cuál es el problema?}

Algunas universidades ofrecen la FI como fortaleza de sus planes de estudio y modelos educativos, respondiendo a las sugerencias de organismos internacionales y nacionales como la Organización de las Naciones Unidas para la Educación, la Ciencia y la Cultura (Unesco), la Organización de Estados Iberoamericanos para la Educación (OEI), la Asociación Nacional de Universidades e Instituciones de Educación Superior (ANUIES), entre otras, las cuales proponen líneas de acción en pro de la formación socioemocional de los estudiantes. Sin embargo, las IES que consiguen apegarse a éstas no han visualizado del todo la voz del alumno, cuando es él quien realmente experimenta los efectos y alcances de los esfuerzos institucionales y de cada docente por hacer posibles sus objetivos para la formación integral.

Este trabajo se propuso ahondar en las experiencias, elementos, actividades académicas y no académicas que los universitarios vinculan a los significados que han 
construido de formación integral. La pregunta que guía esta investigación es: ¿cuáles son los significados que los estudiantes universitarios construyen respecto a la Formación Integral que se promueve en las Instituciones de Educación Superior donde estudian? De esta manera se pretende profundizar en el estudio de las perspectivas de los alumnos, ya que resulta fundamental en la comprensión de los procesos que se ofrecen como formación integral y su valoración por parte de los beneficiarios directos.

\section{Metodología}

Desde un enfoque cualitativo con diseño fenomenológico, la recolección de información inició en febrero de 2018. El que se presenta es un avance de una investigación más amplia, la cual pretende explicitar los significados que construyen los estudiantes universitarios respecto a la formación integral que se imparte en sus instituciones. Para este primer acercamiento se tiene la participación de cinco jóvenes que representan a cada una de las áreas del conocimiento: ciencias exactas e ingeniería, ciencias sociales y humanidades, ciencias económico-administrativas, arquitectura y diseño, y ciencias de la salud. Los estudiantes cursan las carreras de ingeniería mecatrónica, psicología, administración y desarrollo empresarial, arquitectura y nutrición. Están inscritos en una universidad privada de Mérida, la cual forma parte del universo de esta investigación.

Los participantes son alumnos regulares de sexto semestre y se eligieron en respuesta a un muestreo no probabilístico y de participación voluntaria. La dinámica que guio este acercamiento se muestra en la Figura 1.

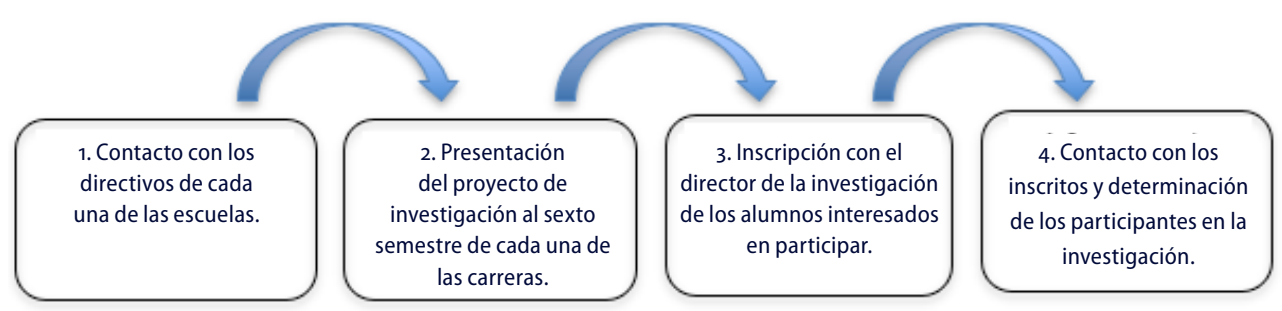

Figura 1. Dinámica de acercamiento

Fuente: Elaboración propia. 
Los jóvenes que aceptaron participar en este estudio tienen entre 20 y 24 años, tres hombres y dos mujeres. Ellos comparten entre sí la motivación de formarse en una carrera profesional, para mejorar su calidad de vida y la de su entorno inmediato; valoran estar en una institución de calidad que se esfuerza por formarlos de la manera más adecuada, sin embargo, reconocen que ésta tiene aún muchas áreas de mejora.

Se utilizaron tres técnicas de recolección de datos que fueron administradas con cada estudiante, en tres momentos diferentes.

Van Manen (2003) considera la recolección de información a partir de técnicas que permitan profundizar en la comprensión de un fenómeno a estudiar. Las técnicas e instrumentos empleados para obtener la información se detallan en la Tabla 1.

\section{Tabla 1. Técnicas para la recolección de información}

\begin{tabular}{|c|c|c|}
\hline Técnica & Instrumento & Objetivo \\
\hline $\begin{array}{l}\text { Reflexiva } \\
\text { Los estudiantes entablaron } \\
\text { un diálogo reflexivo con la } \\
\text { investigadora en relación } \\
\text { a la Fl desde lo que ellos } \\
\text { consideraron como tal. }\end{array}$ & $\begin{array}{l}\text { Entrevista a profundidad } \\
\text { (Merlino, 2009) }\end{array}$ & $\begin{array}{l}\text { Comprender el concepto } \\
\text { y alcances de la formación } \\
\text { integral como construcción } \\
\text { de los alumnos a partir de las } \\
\text { experiencias vividas. }\end{array}$ \\
\hline $\begin{array}{l}\text { Documento académico } \\
\text { Los estudiantes seleccionaron } \\
\text { algún documento de su } \\
\text { área disciplinar producido } \\
\text { por ellos y que, en su } \\
\text { opinión, consideraban como } \\
\text { representativo de la formación } \\
\text { integral. }\end{array}$ & $\begin{array}{l}\text { Guía de análisis } \\
\text { Entrevista semiestructurada } \\
\text { (Díaz, Torruco, Martínez, \& } \\
\text { Varela, 2013) }\end{array}$ & $\begin{array}{l}\text { Profundizar en los significados } \\
\text { de la FI en términos de la } \\
\text { experiencia académica } \\
\text { disciplinar. Y los impactos } \\
\text { identificados en su ser } \\
\text { persona/estudiante. }\end{array}$ \\
\hline $\begin{array}{l}\text { Línea del tiempo } \\
\text { Los estudiantes elaboraron una } \\
\text { línea del tiempo de su vida en } \\
\text { la universidad identificando } \\
\text { una experiencia por semestre } \\
\text { que relacionaran directamente } \\
\text { con la Fl. }\end{array}$ & $\begin{array}{l}\text { Ejercicio de elaboración de } \\
\text { línea del tiempo (Instituto } \\
\text { Nacional de Formación } \\
\text { Docente [INFOD], 2013). } \\
\text { Guía de análisis } \\
\text { Entrevista semiestructurada } \\
\text { (Díaz et al., 2013) }\end{array}$ & $\begin{array}{l}\text { Profundizar en la perspectiva } \\
\text { del joven sobre la FI desde } \\
\text { experiencias académicas } \\
\text { formales, no formales y } \\
\text { extracurriculares para cada } \\
\text { uno de los semestres cursados. } \\
\text { Reconocer el sentido de la Fl } \\
\text { que su institución promueve y } \\
\text { manifiesta. }\end{array}$ \\
\hline
\end{tabular}

Fuente: Elaboración propia. 
Como método de validación de los datos, se recurrió a la triangulación de fuentes. Denzin y Lincoln (2011) argumentan que es un método que tiene la intención y obligación moral de reducir al mínimo las interpretaciones alejadas del sentido que los participantes ofrecen. Este ejercicio de triangulación de información permitió que los resultados que se presentan reflejen el descubrimiento de lo que cada alumno construye respecto a la formación integral a partir de la esencia de las actividades, elementos o procesos que cada participante fue incluyendo en su discurso a partir de los methodos usados.

El método fenomenológico requiere la epojé y la reducción de manera constante; la epojé es un ejercicio de voluntad en el que el investigador intenta suspender toda toma de posición acerca de la existencia o no de los objetos que se nos dan a la conciencia. La reducción, por su parte, permite la reflexión acerca de lo que se ha recibido y que se ha depositado en un proceso de conciencia, el cual puede darse cuando se regresa al participante, a su discurso y a su diálogo para ampliar más la experiencia del mismo, profundizar en su vivencia y significados. Este proceso se llevó a cabo mediante los tres momentos que permitieron confrontar la realidad del investigador respecto al tema que se estudia, al mismo tiempo que logró un mayor nivel de conciencia en el participante, respecto a sus propias explicaciones (Aguirre \& Jaramillo, 2012).

\section{Análisis de resultados}

Las temáticas que se logran vislumbrar han permitido revelar la manera en que los universitarios expresan su concepto de formación integral. Los alumnos compartieron experiencias que dieron la pauta para profundizar en los aspectos que asocian a este tipo de formación y desde dónde la vinculan a su crecimiento personal, académico y profesional. Cada historia expresa una manera diferente de entender la educación y la realidad desde la cual parte cada estudiante; sin embargo, también se observa un posible hilo conductor, que puede interpretarse como la misión, visión y/o filosofía de su universidad y sus intenciones de formación.

Las fases del método fenomenológico describen los contenidos y actividades que tienen su desenlace en los discursos de los estudiantes, los cuales reflejan la esencia del significado que han construido alrededor de la Fi que se promueve en su universidad (Tabla 2). 
Tabla 2. Fases del método fenomenológico

\begin{tabular}{|c|c|c|c|c|}
\hline Fases & Contenido & Actividades & Categorías & Códigos \\
\hline $\begin{array}{l}\text { Fase } 1 \\
\text { Descripción }\end{array}$ & $\begin{array}{l}\text { Recopilación de } \\
\text { las experiencias, } \\
\text { elementos, } \\
\text { actividades que } \\
\text { los estudiantes } \\
\text { relacionan con los } \\
\text { significados que han } \\
\text { construido de Fl. }\end{array}$ & $\begin{array}{l}\text { 1) Entrevista a } \\
\text { profundidad. } \\
\text {-Descripciones } \\
\text { personales. } \\
\text { 2) Análisis de } \\
\text { documentos } \\
\text { académicos } \\
\text { 3) Elaboración y } \\
\text { análisis de líneas del } \\
\text { tiempo. }\end{array}$ & $\begin{array}{l}\text { 1) Dimensiones de } \\
\text { la persona que se } \\
\text { impacta con la Fl. } \\
\text { 2) Aspectos de la } \\
\text { vida universitaria } \\
\text { que relacionan con } \\
\text { formación integral. } \\
\text { 3) Experiencias } \\
\text { que vinculan con } \\
\text { formación integral. } \\
\text { 4) Concepciones } \\
\text { respecto a la } \\
\text { formación integral. }\end{array}$ & \\
\hline $\begin{array}{l}\text { Fase } 2 \\
\text { Interpretación }\end{array}$ & $\begin{array}{l}\text { Análisis y } \\
\text { reflexión sobre las } \\
\text { experiencias que } \\
\text { los estudiantes } \\
\text { expresan respecto } \\
\text { a la FI desde las } \\
\text { diversas situaciones } \\
\text { que viven en la } \\
\text { universidad. }\end{array}$ & $\begin{array}{l}\text { 1) Análisis de los } \\
\text { temas/categorías } \\
\text { que surgen. } \\
\text { 2) Uso de la } \\
\text { reducción } \\
\text { fenomenológica. }\end{array}$ & & \\
\hline $\begin{array}{l}\text { Fase } 3 \\
\text { Descripción e } \\
\text { interpretación }\end{array}$ & $\begin{array}{l}\text { Después de la } \\
\text { reducción se } \\
\text { establecen los } \\
\text { códigos que se } \\
\text { abstraen del discurso } \\
\text { de los participantes, } \\
\text { los cuales reflejan } \\
\text { la esencia de lo que } \\
\text { viven como Fl. }\end{array}$ & & & $\begin{array}{l}\text { *Se } \\
\text { describen } \\
\text { de manera } \\
\text { puntual } \\
\text { en la } \\
\text { redacción } \\
\text { del texto } \\
\text { posterior. }\end{array}$ \\
\hline
\end{tabular}

Fuente: Adaptado de Ayala, 2008.

A lo largo de este apartado se podrá percibir cómo los estudiantes reconocen y confirman entre sus discursos la idea de formación integral como una responsabilidad compartida entre la universidad, como promotora de espacios que permitan la forma- 
ción de una persona que en el futuro pondrá sus conocimientos, habilidades y actitudes al servicio de una profesión, y los universitarios, como participantes activos de la misma. Los relatos de los estudiantes se organizaron en cuatro grandes categorías; las primeras surgen de la teoría revisada y los códigos, del discurso construido por los universitarios. Los comentarios de los alumnos participantes son citas textuales tomadas de extractos de la entrevista a profundidad, y de las opiniones que los estudiantes expresaron en la entrevista semiestructurada que se hizo cuando explicaban las líneas del tiempo y los documentos académicos que presentaron como experiencias que demuestran FI.

Las categorías se irán describiendo desde sus diferentes códigos de análisis y discutiendo a la luz de la teoría que da contexto a esta investigación. Las categorías son:

1. Dimensiones de la persona que se impacta con la FI

2. Aspectos de la vida universitaria que relacionan con FI

3. Experiencias que vinculan con FI

4. Concepciones respecto a la FI

\subsection{Dimensiones de la persona que se impacta con la FI}

De acuerdo con Lonergan (1999), no puede haber formación integral si no se logra impactar o atender las dimensiones biológica, estética, intelectual y valorativa que hacen humano al hombre, pues le permiten sensibilizarse, conocer, maravillarse, tomar decisiones, ser y convivir.

Esta categoría explica aquellas dimensiones de la persona que para los participantes han sido impactadas por experiencias relacionadas a la Fi. En el análisis de la información recabada surgieron seis códigos resultado del encuentro entre las categorías establecidas por el referente teórico y las expresiones de los estudiantes.

\subsubsection{Código 1. Intelectual (conocimientos y habilidades)}

La dimensión intelectual, provista desde la academia y que equivale a los conocimientos propios de una disciplina, es considerada por los universitarios como parte de la FI que debiera promoverse. Los estudiantes que participaron en este estudio no ven la formación académica como algo aislado de su persona, sino como un elemento más de ella, haciendo alusión a que ésta debe ir más allá de la transmisión de información, los debe invitar a pensar y razonar. Un estudiante comentó: 
La parte intelectual es básica, siento que el razonamiento también tiene que ser porque muchas veces los alumnos estudian, ven los ejemplos, ven los ejercicios, pero realmente lo hacen porque el libro lo dice, no porque realmente estén razonando qué está pasando. (A1_ADE)

Otro de los alumnos hace hincapié en que los conocimientos son una característica de la FI encaminada al éxito laboral y en respuesta a la necesidad de desempeñarse en su área de formación con un liderazgo responsable:

Siento que las universidades que ofrecen la formación integral, son universidades que se preocupan por el hecho de que los estudiantes cuando salgan, no salgan a trabajar en lugares que no sea adecuados a su carrera... que cuando salgamos seamos unos ingenieros líderes, pero líderes responsables, ingenieros de vanguardia que tomemos en cuenta no sólo nuestro beneficio; entonces por eso nos ponen estos conocimientos, esas materias. (A2_INGMECA)

Respecto a esta dimensión intelectual, se encuentra una coincidencia importante en Guerra, Mortigo y Berdugo (2013), quienes indican que la formación para el desarrollo del pensamiento, la cognición, las habilidades y aptitudes debe acompañarse de estrategias que prevengan condiciones adversas para el aprendizaje, para lo que sugieren la participación de personas en grupos y ambientes interdisciplinarios y multiculturales que generen retos académicos y de convivencia para el estudiante.

\subsubsection{Código 2. Emocional-Humano}

La dimensión emocional-humana es vista por los estudiantes que participaron en el estudio como un punto muy importante de lo que han vivido como FI, la oportunidad de trabajar aspectos actitudinales y emocionales que les permiten mejorar como personas; sin embargo, reconocen que hace falta mayor promoción de este aspecto en su universidad. Uno de los alumnos comparte:

Cuando estás bien en tus emociones te ayuda a tener una actitud siempre positiva de querer aprender, entonces eso vale más que tener una mente cerrada; te ayuda a buscar innovar, buscar, crear mejores sistemas, mejor organización; en la parte laboral, mejor trato con el cliente, para cerrar tratos, todo eso. Por eso es importante que la universidad tenga esos espacios de formación humana y de valores, pero no todas lo hacen. (A1_ADE)

Un estudiante más dice: "Además de la parte de los conocimientos, la formación integral en la escuela incluye la parte de las emociones, sentimientos y lo social” 
(A3_ARQ). Un tercer comentario al respecto apunta que: "sobre todo en el área de salud, debes tener emociones saludables, pues eso mejora tu trato con el paciente" (A5_NUT). La intención entonces sería orientar lo educativo e incluso lo intelectualacadémico hacia "el cultivo de la razón, la autoconciencia, las emociones y los sentimientos" (Hernández-Jiménez, 2015, p. 85), teniendo presente el ideal de mente sana, el cual implicaría experiencias de reflexión introspectiva, autoconocimiento y meditación, con el fin de lograr una visión desde dentro y propiciar el mejor conocimiento de uno mismo y de los demás miembros de la comunidad universitaria y también como apoyo de la vida espiritual y social del individuo, ya que fomenta su capacidad de relación y comunicación y genera sentido de pertenencia y compromiso con su institución (Guerra, et al., 2013; Hernández-Jiménez, 2015).

\subsubsection{Código 3. Ético-Moral}

La tercera dimensión del ser humano a la que se hace alusión en el estudio es la que refiere a la ética y la moral, vinculada principalmente a la educación en valores que los estudiantes esperan permanezca en la universidad. Ante esto, los alumnos comentan lo siguiente: "los aspectos de la persona que debe abarcar la formación integral es en primera instancia la ética, los valores, el respeto que incluye todo esto de los valores" (A2_INGMECA). Un estudiante más dice al respecto que:

Tendría que tener una formación en valores y respeto hacia las personas, no solamente hacia el círculo económico que está acostumbrado a tratar e igual creo que debería ser como un acercamiento hacia las personas más necesitadas para que él pueda, como que ver cuánta ayuda puede él dar. (A4_PSI)

La dimensión ética-moral se sustenta en primera instancia en la comprensión y ejercicio de la responsabilidad social universitaria. Pretende también reafirmar y reforzar estructuras de valores que favorezcan la construcción de una ética personal que coincida con la que propone la institución formadora (Guerra et al., 2013).

\subsubsection{Código 4. Social}

La social es una de las dimensiones con mayor relevancia en cualquier entorno, y los ambientes educativos no son la excepción, pues se parte de la idea de que la persona es un ser en relación y su desarrollo no es en solitario, tiene la capacidad para vivir entre y con los otros, para transformarse y transformar su contexto inmediato (Asociación de 
Colegios Jesuitas de Colombia [ACODESI], 2003; Hernández-Jiménez, 2015). Así lo expresan los estudiantes al hablar de cómo lo que ellos construyen alrededor de la Fi les permite tener un impacto positivo en su relación con los otros. Un alumno comentó:

siento que ahora soy capaz de ver más cosas que antes, puedo tomar en cuenta más situaciones, puedo ver con más claridad porque a veces la gente piensa esto o lo otro... inclusive cuando tengo que callarme, el hecho de saber cuándo hacer silencio también me ha ayudado mucho. Siento que maduré a la hora de hablar, porque antes era muy imprudente cuando decía las cosas. El hecho de pensar antes de hablar, también soy mucho más organizada que antes y ahora expreso más, soy más asertiva. (A4_PSI)

Otra estudiante comparte: "he tenido mucho crecimiento en lo social, más que nada en la convivencia y confianza que tenemos con nuestros compañeros, hacemos equipos todo el tiempo, nos enseñan a respetar, a tolerar” (A3_ARQ).

\subsubsection{Código 5. Espiritual}

La dimensión espiritual que se describe desde la teoría, sostiene que la misma no se postula desde una posición dogmática o doctrinal determinada, sino que se invita a valorar diferentes manifestaciones de religiosidad en vías de la trascendencia que dé sentido y coherencia a la existencia del ser humano (Hernández-Jiménez, 2015). Sin embargo, Guerra et al. (2013) plantean una formación espiritual que permita el diálogo entre religiones que construya lazos de tolerancia y convivencia. Fischman (2017) complementa estas ideas diciendo que la espiritualidad es vista como una fuerza inherente al ser humano, que se nutre de experiencias individuales y trascendentes que llevan a la persona a replantearse su sentido de vida, alejándose de la premisa de que la dimensión espiritual se reduce a creencias religiosas.

Vista desde el discurso de los estudiantes, esta dimensión espiritual y su impacto desde la FI, gira en torno a replantearse el papel de la religión desde sus conceptos dogmáticos y el descubrimiento de la espiritualidad más allá de determinada religión, pero no como una responsabilidad directa de la universidad. Una estudiante de psicología comenta:

Descubrí que... si bien soy católica y que para mí el creer siempre ha sido como que un poco difícil, el saber información de psicología transpersonal fue como un parteaguas, como saber que puedo tener una dualidad en relación a las cosas que creo... y creo que eso, como que me fortalece. (A4_PSI) 
Con base en la experiencia de esta alumna se observa que los conocimientos y la conciencia generada desde las temáticas de una clase le permitieron darse cuenta de la dimensión trascendente (espiritual). Entonces, el papel de la universidad no fue "enseñarle" espiritualidad, sino permear el espacio para que ella descubriera la posibilidad de un desarrollo espiritual, incluso sin ser una intención deliberada de la institución o de la clase. Otro estudiante platica al respecto que: "las cuestiones de sentido de vida siento que se empiezan en la casa, es poco lo que la universidad puede hacer; o sea, creo que no saben cómo hacerlo" (A2_INGMECA).

\subsubsection{Código 6. Ambiental-Contextual}

Los cuatro pilares de la educación planteados por Delors en su informe de 1996: aprender a conocer, aprender a hacer, aprender a ser y aprender a vivir juntos, son la base de muchos modelos educativos e inspiración de estrategias para dar respuesta a las fuertes demandas que la sociedad realiza a la educación en general. Sin embargo, considerando la realidad de un entorno cada vez más deteriorado y la poca conciencia que se generaba al respecto, adicional a esos cuatro pilares, Tedesco (2003) propone un quinto pilar que refiere a "proporcionar los instrumentos necesarios para transformar las actuales sociedades en sociedades más sostenibles" (p. 32) (como se citó en Casalvázquez, 2015, p. 7), pilar que apunta hacia el aprender a trascender. Independientemente de que de manera deliberada se sostenga y se argumente la necesidad de una conciencia ambiental y de conocimiento del entorno, respecto a esta dimensión, se encuentran en el discurso de los participantes algunas experiencias acerca del impacto que tiene la formación integral en un posible aspecto de conciencia ambiental:

Nos dijo: "entonces imaginen cuántos salones hay en la universidad, cuántos salones tienen prendida la luz, el aire, los ventiladores, las direcciones y coordinaciones y lo planteo como gastos innecesarios que está teniendo la universidad y son gastos que ustedes no deben provocar en una empresa, no tanto por el gasto, sino por el medio ambiente". Creo que estas enseñanzas son características de la universidad y que los maestros siempre abordan estos temas para que nosotros hagamos conciencia. Y yo todo el tiempo ya estoy pensando en cuánto consumo hay en equis lugar y en el impacto ambiental, por eso ya soy más consciente y trato de evitar consumir de más en mi casa y también en la escuela, y a mi familia siempre se los digo. (A2_INGMECA) 
Un participante más indica en relación a la importancia de conocer y valorar el contexto:

Pero también siento yo que algunas materias y algunos maestros te hacen querer conocer al país y tienes que saber cómo está el país en todos los sentidos, ambiental, económico, etcétera, para que tú puedas hacer algo, puedas innovar, puedas crear un producto, puedas crear algún servicio en cuanto a tu carrera, ¿no? Porque no en cualquier circunstancia vas a poder llegar y hacer algo que no puedes o algo que no funcione para ese lugar o que lo ponga en riesgo. (A1_ADE)

El ser humano se concibe como un todo integrado por subsistemas y cada uno de ellos es una dimensión a formar, dimensiones que de manera coordinada constituyen la personalidad. Para esto, se espera una ruta educativa que incluya diversos caminos que respondan a los intereses, necesidades y gustos de cada ser, se espera una "educación integral que tome en cuenta el desarrollo neurofisiológico; cognitivo, inteligencia y creatividad; psicológico, afectivo y social; moral, ético y de valores; y vocacional y profesional de las personas" (Martínez, 2009, pp. 124-129).

\subsection{Aspectos de la vida universitaria que se relacionan con la formación integral}

Al igual que la anterior, esta categoría se subdivide en seis códigos de análisis, los cuales surgen de los estudiantes en la verbalización de sus experiencias. Los códigos que se identificaron son:

\subsubsection{Código 7. Docencia}

El papel de los profesores es fundamental, se reconoce la importancia de la interacción que el maestro establece con los estudiantes como un factor que permite una educación que forma más allá de los contenidos y que impacta las diferentes dimensiones de la persona a quien forman (Aguiar, Montoya \& Céspedes, 2013). La vocación docente es un elemento clave en la manera como los alumnos perciben a sus profesores; características como: creer en los estudiantes, aprender y creer en ellos y la valoración que el mismo maestro da a su práctica (Patiño, 2015), son aspectos que los universitarios valoran en un docente relacionándolo de manera directa como un medio que fortalece la educación integral en una universidad. Uno de los estudiantes comenta: 
Como te enseñan, la dedicación de los maestros, toman tu opinión, la cercanía y confianza que te contagian, logra que tengamos compromiso con la clase y para aprender mejor. También los maestros nos ayudan a tener experiencias fuera de las clases y poder conocer cómo operan algunas empresas, como tipo prácticas. (A5_NUT)

Otro alumno comparte al respecto:

O sea, los maestros de cajón deben enseñarte los contenidos, deben ser estratégicos, como que lleven algún planteamiento, que tengan metas bien establecidas, pero también siento que deben preocuparse por sus alumnos, no sólo en lo académico sino también en lo personal, porque pienso que igual eso tiene que ver para que un alumno se sienta cómodo y se sienta tranquilo en la escuela que está. Que se involucren un poco, que tengan el tacto de platicar con ellos de sus problemas. (A2_ARQ)

Cada espacio educativo se vuelve una fortaleza que emana posibilidades para resignificar el pensamiento del profesor, con el fin de ir descubriendo la importancia de generar habilidades sociales incluyentes de la dimensión afectiva y emocional en la formación, y progresivamente "eliminar la tendencia gradual de muchos docentes a suprimir sus emociones cuando enseñan, o tratar de evitar las expresiones afectivas de los estudiantes por considerarlo riesgoso al manejo del grupo" (Cienfuegos, 2013, p. 5).

\subsubsection{Código 8. Currículum}

Pensar en programas académicos que integren temáticas que van más allá de la formación en una disciplina representa un reto para las universidades, pues se debe responder a dos líneas muy demandantes: por un lado, formar profesionistas que respondan a las exigencias del mercado, y por otro, profesionistas que sean socialmente responsables y que den respuestas éticas a las grandes problemáticas de nuestro entorno. "Diseñar un currículo para la formación integral requiere una concepción del hombre ajustada al actual sistema de pensamiento complejo, que lo identifica como un ser antropobiopsicosocial. Para esto, el proceso educativo procurará, de modo holístico, el desarrollo del educando" (Vallejo, 2001, p. 3). A partir de este marco, es posible entender la explicación que dio un joven, el cual percibe de manera general que son pocas las materias que promueven deliberadamente una formación ética o en valores o que incluyen conocimientos del contexto socio-ambiental: 
En ciertas clases, definitivamente no en todas las clases, se da esa formación ética. Había una materia en la que nos íbamos como que informando de lo que pasa en nuestro medio, de corrupción, política y de ese tipo de cosas, y cómo influye todo eso en la tecnología, con el medio ambiente, o sea, sí platicamos de lo que pasa en el país. (A1_ADE)

Así también, uno de los participantes apunta hacia la necesidad de materias que impliquen desde su creación la práctica guiada por el profesor y sustentada desde la teoría:

Me gustaría que no sea tan teórico, relacionaría lo visto en los salones con la realidad, o sea, tener materias que estén enfocadas a la práctica, pero guiada por el maestro; o sea, que regresemos al salón a relacionar con la teoría y diciendo lo que vivimos en la práctica, podemos aprender más de las experiencias de todos, no solo de si sabes a, b, c... (A5_NUT)

\subsubsection{Código 9. Investigación}

En relación a la función sustantiva de investigación en las universidades, Santacoloma (2012) asume y promueve que los semilleros de investigación van en aumento y que han adoptado formas distintas de funcionamiento, permitiendo la conformación de diversos grupos, entre los que se observan: de estudio, de apoyo a los grupos de investigación formal, de lectura, de escritura, de trabajo en desarrollo tecnológico, entre otros. Estas actividades desarrollan en los alumnos habilidades de pensamiento crítico, análisis y síntesis, resolución de problemas, así como actitudes colaborativas y de trabajo honesto; es decir, la investigación es una vía muy contundente para la formación integral. Dos estudiantes, desde la experiencia que han tenido en su trayectoria universitaria, comparten lo siguiente:

Los coloquios de investigación donde nos unen todas las materias en un solo trabajo de investigación es hasta ahorita lo que más enfoco como formación integral. El semestre pasado sí sentí que tuve formación integral, con la materia de investigación de mercados, porque realmente te exige mucho esa materia en cuanto a la redacción de trabajo de investigación, saber de matemáticas por el área de estadística, te exige manejar programas que realmente te van a ayudar, como el SPss; además de la convivencia con el equipo al momento de la realización del trabajo, la paciencia, la tolerancia, el que todos exploten sus habilidades, para qué es bueno cada quien... (A1_ADE) 
Un estudiante más comenta: "Para mí, parte de la formación integral es el laboratorio y todo lo que aquí hago; ayudo a la maestra y he aprendido muchas cosas, como conocer los instrumentos y máquinas, de esto me nació el gusto por la investigación” (A5_NUT).

\subsubsection{Código 10. Extensión y vinculación}

La extensión y vinculación en la universidad desempeña una función vital para la misma, pues contribuye de manera directa con la FI y profesional de los estudiantes, promoviendo transversalmente desde sus acciones la prestación de servicios, la pertinencia social y el desarrollo económico-social del entorno local y nacional (Ruiz, 2009). Tomando en cuenta el Modelo de Tercera Función Universitaria, Ejea y Garduño (2014) agrupan en cuatro tipos las actividades de extensión: a) artes y deportes; b) divulgación del conocimiento; c) prestación de servicios a la comunidad; d) intercambio y vinculación institucional. Visto desde este marco, los estudiantes compartieron dos tipos de experiencias relacionadas a la extensión como un aspecto que abona a la formación integral; una enfocada a la convivencia inter-carreras, dando énfasis a las actividades extracurriculares, y otra respecto a actividades que amplían la base de conocimientos de los alumnos: "el carnaval de ingeniería. Es algo que organizaron en la universidad y no se me olvida para nada. Fue un momento de convivencia padre entre maestros y alumnos de ingenierías" (A2_INGMECA). Otro alumno comenta: "la universidad brinda bastantes cursos y eso también es importante si intentan formarte de manera integral; brindan cursos que algunos te sirven para valor curricular, algunos sólo de carácter informativo, algunos más, pláticas motivacionales, pero sí son útiles" (A1_ADE).

\subsubsection{Código 11. Servicio y desarrollo comunitario}

El servicio y desarrollo comunitario como aspecto que fomenta la Fi en los estudiantes es entendido, en palabras de Guevara (2017), como el compromiso de las instituciones de educación superior para que proporcionen a la sociedad herramientas plasmadas en sus egresados, que se dirijan al logro de cambios sociales orientados a la búsqueda de calidad de vida y bienestar de la población. Para esto considera tener espacios de formación formal y no formal que promuevan la actitud de servicio, el formarse para el bienestar social y tener actividades y materias que permitan este análisis, apun- 
tando así a la transformación del ser, como sujeto activo, capaz de transformar y ser transformado, desde una óptica de lo humano. Dentro de los espacios de formación formal, dos de los estudiantes entrevistados consideran que desde su servicio social viven la FI, pero más enfocado hacia el desarrollo de la ética, la honestidad y el crecimiento profesional:

En mi servicio creo que hay una formación integral importante, el hecho de no usar piratería, por ejemplo; con el que estoy trabajando me dice: las reglas son sencillas, si tú vas a usar un PDF compra el libro antes; siempre hay que ser ético, porque al autor le afecta, él trabajó mucho para que llegue hasta ahí. (A2_INGMECA)

El segundo alumno comenta: "Ubico la formación integral sobre todo en mi servicio, me gusta mucho el laboratorio, aprendo de mi tutora y estoy en contacto con los alumnos de otros semestres. Es una buena oportunidad para aprender" (A5_NUT). Estos comentarios abonan a la idea de valorar el aprendizaje entre pares y centrado en la realidad, como aspectos que fortalecen su formación integral.

Tal como se observa, aunque este elemento (servicio y desarrollo comunitario) lo vinculan a la FI, no lo consideran como un aspecto que los lleve a prácticas para la transformación social, como lo afirma Guevara (2017). Lo que pareciera indicar que, en este momento de vida, los alumnos no se vislumbran como agentes de cambio social, sino como aprendices que todavía tienen que transformarse ellos mismos.

\subsubsection{Código 12. Políticas y prácticas institucionales}

Las políticas y prácticas institucionales son fundamentales, pues permiten una visión clara de la institución como unidad sistémica, en la cual sus componentes deben funcionar con coherencia en sí mismos y con el sistema total, respondiendo a la misión y visión de la institución (Vallejo, 2001). Desde lo que significa para ellos, los estudiantes vinculan la Fi con algunas prácticas y elementos que conforman su universidad, como por ejemplo el espacio de la biblioteca:

La biblioteca es importante para la formación integral, pero me choca, porque tú vas y como que tienes que buscar en la computadora el libro y a veces lo tienen, pero no puedes entrar y ver los libros, hojearlos para ver si realmente te sirven, porque todos los libros están en resguardo, y además está muy chica [la biblioteca] y me estresa y debería haber salones para estudiar. (A4_PSI)

Dos estudiantes más reconocen como prácticas institucionales el contacto con los directivos, y como un elemento muy importante de la FI: "El trato y la cercanía con 
los directivos sería muy importante, pues ellos son lo principal para que puedan contagiar la formación integral" (A4_PSI). Un estudiante más comenta: "Yo esperaría que los directivos sean más cercanos a los alumnos, que nos escuchen, que escuchen nuestras necesidades" (A5_NUT).

\subsection{Experiencias que se vinculan con formación integral}

Cuando se habla del término experiencia en el ámbito educativo frecuentemente se relaciona con procesos vinculados al aprendizaje y la enseñanza, así como a situaciones que involucran el comportamiento de profesores y alumnos derivado del encuentro entre éstos.

Guzmán y Saucedo (2015) refieren respecto a este término que:

el uso generalizado de la noción de experiencia se debe a sus múltiples significados y se trata de un concepto polisémico y hasta cierto punto confuso. La experiencia es una noción muy arraigada en el sentido común y se le usa cotidianamente de múltiples maneras. (p. 1023)

En el abordaje de las ideas que se iban generando en las entrevistas, se reconoce información relacionada a experiencias que los universitarios vinculan directamente a la formación integral. Para el análisis de éstas se distinguen dos códigos: experiencias personales y experiencias académicas.

El concepto de experiencia que se toma en cuenta en las vivencias y los sentidos es el que considera la reconstrucción de significados, poniéndolos en acción o narrando la experiencia misma como una capacidad del individuo (Guzmán \& Saucedo, 2015). A continuación, se describen las aportaciones de los alumnos.

\subsubsection{Código 13. Experiencias personales}

Hay un maestro con el que nos fue muy mal y él habló con nosotros, y escribió nuestros nombres en el pizarrón y nos pidió que el que quisiera escribiera un compromiso respecto a la materia y lo que íbamos a hacer para mejorar (algunos fueron y otros no fueron por pena o porque no les importa). O sea, eso no está en el programa, pero sí nos sirvió (bueno, a mí) como persona, en mi compromiso y para mejorar. Son experiencias que nos marcan porque nos van a ayudar en un futuro para ser más puntuales y tener más compromiso. (A2_INGMECA) 
Experiencia tal vez no nueva, pero sí para seguir aprendiendo, porque yo por lo general trato con personas de negocios, para cerrar contratos en cuanto a obras, porque donde trabajo es una constructora con mi papá; entonces, en el momento en el que creamos la empresa y tuvimos que hablar ante ese jurado, entonces te das cuenta de sus reacciones del jurado, y cómo tú te desenvuelves y empiezas a escuchar lo que tú estás diciendo y te fijas si lo estás diciendo bien... entonces son esos detalles de los que aprendes, te vuelves más observador de tus propios procesos. (A1_ADE)

\subsubsection{Código 14. Experiencias académicas}

Hicimos una máquina dispensadora de comida de perro con botellas de PET, y el ejercicio era que metías tres botellas de PET, presionabas un botón y se dispensaba comida de perro; $y$ ya, pues lo presentamos y era un proyecto que visualmente era feo, la verdad no tenemos ese detalle que puede tener un diseñador, pero al fin y al cabo, cuando entregaron los diplomas de reconocimiento, nosotros ganamos tres diplomas. Fue el proyecto que tuvo más reconocimientos, y es algo que igual no se me va a olvidar de por vida. Aprendí mucho de los aspectos que un ingeniero mecánico debe considerar al momento de crear algo. (A2_INGMECA)

Un alumno más comparte respecto a las experiencias académicas que "en los congresos y las jornadas de salud, [...] aprendes cosas nuevas de temas generales que se relacionan con tu carrera, y también aprendes y te das cuenta que puedes hacer muchas cosas a la vez" (A5_NUT).

Para los estudiantes que participaron en el estudio, ambos tipos de experiencias las encontraban como momentos llenos de significados, que en su conjunto abonaban a un tipo de formación que iba más allá de la memorización de conceptos y puede asociarse con solución de problemas en ambientes complejos; se llevaban aprendizajes que no podrían adquirir si las clases o experiencias se limitaran a la transmisión de conocimientos.

\subsection{Concepciones respecto a la formación integral}

Considerando el recorrido a la luz de la Fi que los estudiantes que participaron en la investigación realizaron respecto a su trayectoria universitaria (línea del tiempo), lograron construir un concepto propio de FI. Para esto se distinguen dos vertientes 
definidas en dos códigos: lo que es y lo que no es FI. A continuación, se describen las aportaciones de los estudiantes:

\subsubsection{Código 15. Lo que es formación integral}

Los cinco estudiantes compartieron, de acuerdo con las experiencias que han tenido, lo que para ellos es formación integral:

"Es una educación íntima, una formación educativa del área social y ética" (A2_INGMECA).

"Unir las diferentes áreas del conocimiento para ejercer algo" (A1_ADE).

"Tipo de educación que toma de otras disciplinas lo necesario para hacer un programa de estudios (por ejemplo, en esta parte a mí sí me gustaría tomar materias de otras carreras, pero no nos dejan...)” (A4_PSI).

"La formación integral va a permitir que un profesional que sea egresado cuente no sólo con el conocimiento sino también con habilidades y valores que formen a la persona” (A5_NUT).

"Incluye aspectos como la sensibilidad, lo psicológico, lo social" (A3_ARQ).

Cada una de estas aportaciones responde a lo que Orozco (1999) y López (2014) articulan como formación integral, pensando ésta como un estilo educativo, en el que además de transmitir conocimientos o saberes de una profesión, también ofrece espacios para el desarrollo personal, promoviendo así un tipo de educación que abone al desarrollo de las dimensiones ética, espiritual, cognitiva, afectiva, comunicativa, estética, corporal y sociopolítica, teniendo como marco de referencia el respeto a la dignidad humana.

A los estudiantes también se les preguntó en qué momento sentían que su universidad no promovía esa formación integral que ellos habían definido, a lo que respondieron con lo que se describe en el siguiente código de análisis (código 16).

\subsubsection{Código 16. Lo que no es formación integral}

"Siento que cuando nos quedamos solamente con los libros, en los conocimientos y no vemos más allá” (A4_PSI). En relación a este comentario, Ruiz (2002) explica el caso de México e indica que desde su Constitución concibe la FI como su fin, pero por la influencia de la globalización económica y de responder a un sistema capitalista, la educación superior se ve comprometida con otro fin que prioriza "la 
información sobre la formación, la rentabilidad sobre la cobertura, el éxito individual sobre el beneficio colectivo" (p. 93), dejando de lado los aspectos sociales y humanos. Las experiencias de los otros estudiantes giran alrededor de profesores que dejan de cumplir su función como gestores de situaciones que le permiten al alumno tener en cuenta la "capacidad de ejercer acciones conjuntas, hacer bien las cosas, enriquecer y orientar sus desarrollos buscando ser mejores seres humanos" (Escobar, Franco \& Duque, 2010, p. 76). La experiencia de uno de los estudiantes es la siguiente:

Maestros que ya tienen mucho tiempo y son, por decir así... barcos. Me tocó un maestro que decía, si no vas por mi refresco o mi torta, no cuentes con estos puntos, y una vez dije, no voy a ir, y me bajaron los puntos. (A2_INGMECA)

Otro alumno comenta: "cuando imparten sus materias los maestros y no le toman la seriedad como si fuese una universidad, a veces la toman como si fuese un juego. Maestros barco" (A1_ADE).

\section{Conclusiones}

Los desafíos que la sociedad contemporánea ofrece a las IEs son complejos; una economía frágil y plagada de incertidumbres, estructuras sociales claramente injustas y una generación marcada por la inmediatez y aparente despreocupación por lo que sucede en su entorno. En este contexto, las universidades no pueden seguir reproduciendo verdades absolutas en nombre de la FI, pues se necesitan respuestas urgentes para una sociedad que requiere de estudiantes y futuros profesionales en cuya formación se trascienda la idea de responder a modelos económicos.

La formación integral como un estilo de educar "se enfoca en el estudiante como un todo, lo conduce a actuar desde el potencial de su espíritu y de manera autónoma y responsable en su contexto social" (Orozco, 1999, como se citó en Nova, 2017, p. 189), buscando como fin el compromiso con su propia transformación y la de su entorno.

La educación superior, considerada por los estudiantes como el último escalón en la formación académica formal de una persona, lleva a pensar la universidad como el espacio donde exista la responsabilidad de formar profesionales que se comprometan con la construcción de una sociedad más responsable y justa; sin embargo, se puede entender que, a partir de las voces de los estudiantes, la Fi toma significados que las instituciones no declaran en sus objetivos; pero también que dejan de lado aspectos que tradicionalmente han sido considerados como la formación ética y en 
valores. Esto sugiere que los procesos que permitan al ser humano aprender del ser humano desde el ser, el conocer, el hacer, el convivir y el trascender (Delors, 1996; Tedesco, 2003), sean tratados con la misma importancia en la planeación y acción de las IEs. De ahí el interés de que la fi que las universidades promueven, tome en cuenta los elementos que los alumnos experimentan como fi y el significado que les va generando.

Uno de los puntos que los estudiantes consideraron importantes para su FI, pero la universidad no lo hizo, es el relacionado con el manejo de emociones y la mediación de conflictos. Los jóvenes consideran que es una competencia poco trabajada desde intenciones académicas, y que para ellos es muy importante porque les brindaría elementos que en su vida profesional serían de gran valor, como en la negociación de precios y condiciones, contratación de personal, trato del paciente como persona, etc. Sin embargo, consideran que no se ofrecen esos espacios de manera formal. Alguno de ellos valoró los ambientes interdisciplinarios para aprender y/o desarrollar habilidades para la toma de acuerdos; pero no como un aspecto deliberado, sino casual.

Otro punto que fue mencionado por los jóvenes es el relacionado con la concientización sobre los asuntos ambientales. Los alumnos que participaron en este estudio opinaron que es algo que ellos ya han aprendido, pero que la universidad debería reforzar, pues por ahora este aspecto se trabaja por algunos profesores, pero de manera implícita y no como una intención institucional ni un común denominador a todos los profesores y alumnos.

Un tercer punto que los estudiantes señalaron fue la dimensión espiritual. Piensan que actualmente es vista únicamente desde un aspecto religioso y como parte de un proceso propio de reflexión. No reconocen un trabajo institucional respecto a la formación en una dimensión que los lleve al análisis del significado de la trascendencia y la construcción-revisión constante de su sentido de vida. Sin embargo, los contenidos de ciertas clases han permitido el análisis de su propia dimensión espiritual sin ser esa la intención principal; los jóvenes reconocen que ésta es un aspecto de la FI.

La investigación fue mencionada como una experiencia de aprendizaje que promueve la FI, pues les permite hacer coincidir un repertorio amplio de conocimientos, habilidades y actitudes. Generalmente, la universidad incluye la investigación como parte del currículo, pero los jóvenes consideran que con objetivos muy específicos de aprendizaje de contenidos y no como experiencias de formación. La universidad aún no ha descubierto la gran oportunidad de Fi que las actividades de investigación tienen y que los alumnos valoran. 
Resulta clara la importancia de una formación que trasciende el "saber hacer" y conducir la formación al "saber ser", en cuanto la formación de la conciencia sobre sí mismo y sobre su relación con los demás y con el mundo; desde esta óptica, los hallazgos que se revelan sugieren posibilidades desde la voz de los estudiantes que podrían ser aportaciones para la planificación de las propuestas de FI institucionales.

En este sentido y teniendo como marco de referencia los cinco pilares de la educación (Delors, 1996; Tedesco, 2003), vale la pena revisar la preocupación de los jóvenes por desarrollar la gestión saludable de sus emociones; así como también las habilidades para establecer relaciones constructivas que se manifiesten en la solución de conflictos a través del diálogo. Esto, considerando que la universidad es vista como un escenario de mucha satisfacción, pero también generador de altos niveles de estrés que, aunado a la historia personal, se vuelve un detonador de emociones ambivalentes que pocos estudiantes saben manejar. Apuntando a la idea del aprender a ser y aprender a trascender, se observa como una prioridad tener una línea deliberada de acción acerca de la conciencia ambiental y para el conocimiento y análisis del contexto social, respondiendo a una necesidad observada por los universitarios de un tema que pasa desapercibido.

Desde el aprender a convivir, hacer y saber, los estudiantes reconocen: 1) la necesidad de que de manera institucional se promuevan proyectos interdisciplinares desde problemáticas reales, identificadas por ellos mismos en sus espacios o áreas de servicio y difundidas por la universidad desde una línea clara de acción que les permita poner en práctica los conocimientos y habilidades que van adquiriendo en su formación profesional, y 2) plantear el "aprender investigando" y promover la investigación como una intención deliberada para la FI, con los beneficios que ésta conlleva para el desarrollo personal y profesional y no sólo como una materia del plan de estudios.

Siendo los docentes un nexo reconocido abiertamente por los estudiantes entre la institución y el alumnado, estos últimos depositan en los maestros, en su práctica y en su trato, muchos de los logros que se obtienen de los intentos institucionales por formar integralmente a los universitarios. En esta línea se sustenta la formación en el aprender a ser, convivir, hacer, conocer y trascender desde y para el cuerpo de docentes de la universidad, promoviendo espacios que permitan el diálogo con profesores (entre profesores, de profesores con estudiantes y de directivos y profesores) respecto al rol del docente universitario, para considerar relaciones más cercanas con los estudiantes, basadas en el reconocimiento del otro como persona y el compromiso deliberado con la formación integral de los estudiantes; permitiendo acercamientos 
importantes hacia el análisis interinstitucional que haga posible: 1) definir la forma como las IEs entienden la formación integral y lo que intentan lograr en sus estudiantes; 2) definir el papel del profesor como promotor constante de la FI, y 3 ) clarificar y difundir entre la comunidad universitaria las líneas o ejes de acción que abonarán a cada una de las dimensiones de la persona en formación, de manera creativa y donde los estudiantes tengan una participación directa y constante.

Los hallazgos que surgen de esta investigación nos invitan a pensar que las aportaciones de los jóvenes podrían enriquecer los planteamientos institucionales. Este trabajo no sólo nos motiva a revisar la Fi que se promueve en las universidades, sino también a preguntarnos si existen canales de comunicación abiertos para escuchar a los jóvenes.

\section{Lista de referencias}

Aguiar, F., Montoya, J., \& Céspedes, A. (2013). El maestro, su formación y su rol en la educación contemporánea en Ecuador. Odiseo. Revista Electrónica de Pedagogía, 1o(19). Recuperado de https://odiseo.com.mx/articulos/maestro-suformacion-su-rol-en-educacion-contemporanea-en-ecuador

Aguirre, J., \& Jaramillo, L. (2012). Aportes del método fenomenológico a la investigación educativa. Revista Latinoamericana de Estudios Educativos, 8(2), 51-74.

Asociación de Colegios Jesuitas de Colombia. (2003). La formación integral y sus dimensiones. Bogotá: Autor.

Ayala, R. (2008). La metodología fenomenológico-hermenéutica de M. Van Manen en el campo de la investigación educativa. Posibilidades y primeras experiencias. Revista de Investigación Educativa, 26(2), 409-430. Recuperado de http:// revistas.um.es/rie/article/view/94001

Casalvázquez, G. (2015). Educación para el desarrollo sostenible: una nueva mirada para abordar los problemas desde la educación permanente. Madrid: Universidad Complutense de Madrid/Educación e Innovación.

Cienfuegos, M. (julio-diciembre, 2013). El pensamiento docente en torno a sus habilidades sociales con alteridad para el ser y convivir como parte de la formación integral. Revista Iberoamericana para la Investigación y Desarrollo Educativo, 11.

Delors, J. (1996). La educación encierra un tesoro. París: Organización de las Naciones Unidas para la Educación, la Ciencia y la Cultura/Santillana. 
Denzin, N., \& Lincoln, Y. (Coords.). (2011). Manual de investigación cualitativa. El campo de la investigación cualitativa (Vol. 1). Barcelona: Gedisa.

Díaz, L., Torruco, U., Martínez, M., \& Varela, M. (octubre-diciembre, 2013). La entrevista, recurso flexible y dinámico. Investigación en Educación Médica, 2(7), 162-167. Recuperado de http://riem.facmed.unam.mx/node/47

Ejea, T., \& Garduño, B. (2014). La Extensión de la Cultura Universitaria en México: Un ensayo sobre su historia, conceptualización y relevancia. En H. Méndez \& F. Cuamea (Eds.), Universidad, ciencia y cultura: evocaciones para un saber colectivo. México: Universidad Autónoma de Baja California.

Escobar, M., Franco, Z., \& Duque, J. (enero-diciembre, 2010). La formación integral en la educación superior. Significado para los docentes como actores de la vida universitaria. Revista Eleuthera, 4, 69-89. Recuperado de http://200.21.104.25/ eleuthera/index.php?option $=$ com content $\&$ view $=$ article $\&$ id $=114$

Fischman, D. (2017). Inteligencia espiritual en la práctica. México: Planeta.

Guerra, Y., Mórtigo, A. M., \& Berdugo, N. C. (2013). Formación integral. Importancia de formar pensando en todas las dimensiones del ser. Revista educación y Desarrollo Social, 8(1), 48-69. Recuperado de https://revistas.unimilitar.edu.co/ index.php/reds/article/view/585

Guevara, C. (abril-septiembre, 2017). Servicio comunitario, aprendizaje-servicio y formación social: claves para la construcción de espacios transformativos universitarios. Revista Electrónica de Humanidades, Educación y Comunicación Social, 23, 85-87. Recuperado de http://ojs.urbe.edu/index.php/redhecs/article/view/714

Guzmán, C., \& Saucedo, C. (octubre-diciembre, 2015). Experiencias, vivencias y sentidos en torno a la escuela y a los estudios. Abordajes desde las perspectivas de alumnos y estudiantes. Revista Mexicana de Investigación Educativa, 20(67), 1019-1054. Recuperado de https://www.comie.org.mx/revista/v2018/rmie/ index.php/nrmie/article/view/157

Hernández-Jiménez, D. (2015). Educación: una visión desde las dimensiones del ser humano y la vida. Revista Acta Académica, 57, 79-92.

Instituto Nacional de Formación Docente. (2013). Enseñar y aprender con líneas del tiempo. Argentina: Red INFOD.

Lonergan, B. (1999). Insight. Estudio sobre la comprensión humana. Salamanca: Sígueme.

López, M. (2014). Ser persona y hacerse persona en el cambio de época: desafíos para la formación integral en la escuela y la universidad. Revista Latinoamericana de Estudios Educativos, 64(3), 61-81. 
Manen van, M. (2003). Investigación educativa y experiencia vivida. Ciencia humana para una pedagogía de la acción y de la sensibilidad. Barcelona: Idea Books.

Martínez, M. (2009). Dimensiones Básicas de un Desarrollo Humano Integral. Polis, Revista Latinoamericana, 8(23), 119-138. Recuperado de https://journals.openedition.org/polis/1802

Merlino, A. (2009). Investigación cualitativa en ciencias sociales. Buenos Aires: Cengage Learning.

Misas, G. (2004). Colombia aprende. La educación superior en Colombia: Análisis y estrategias para su desarrollo. Colombia: Universidad Nacional de Colombia.

Morín, E. (1999). Los siete saberes necesarios para la educación del futuro. París: Organización de las Naciones Unidas para la Educación, la Ciencia y la Cultura.

Nova, A. (2017). Formación integral en la educación superior: análisis de contenido de discursos políticos. Praxis y Saber, 8(17), 192-195. Recuperado de https:// revistas.uptc.edu.co/index.php/praxis_saber/article/view/7206

Orozco, L. (1999). La formación integral: Mito o realidad. Universitas, Revista de Ciencias Sociales y Humanas, 10, 161-186.

Patiño, H. (2015). ¿Qué hacen los docentes de excelencia? Claves para la formación humanista en la universidad. México: Universidad Iberoamericana.

Pérez, A. (2011). ¿Para qué educamos hoy? Filosofía de la educación para un mundo nuevo. Argentina: Biblos.

Ruiz, A. (2002). Educación superior y globalización. Educar ¿para qué? México: Plaza y Valdés.

Ruiz, L. (2009). Paradigmas de la vinculación. Una visión de la ANUIES. México: Universidad Juárez Autónoma de Tabasco.

Santacoloma, A. (2012). Los semilleros investigación como estrategia de formación integral para ciudadanos del tercer milenio. Revista Cultura, Educación y Sociedad, 3(1), 14-18. Recuperado de https://revistascientificas.cuc.edu.co/culturaeducacionysociedad/article/view/952

Tedesco, J. (2003). Los pilares de la educación del futuro. Ponencia presentada en el ciclo Debates de educación de la Fundación Jaume Bofill y la Universidad Abierta de Cataluña, Barcelona.

Vallejo, M. (2001). Diseño curricular para la formación integral. Revista Unipluriversidad, 1(2), 3-5. Recuperado de http://aprendeenlinea.udea.edu.co/revistas/ index.php/unip/article/view/12254 